\title{
Strongyloides stercoralis infection after the use of emergency corticosteroids: a case report on hyperinfection syndrome
}

\author{
George Vasquez-Rios ${ }^{1,2^{*}}$ (D), Roberto Pineda-Reyes ${ }^{2}$, Eloy F. Ruiz ${ }^{3}$, Angelica Terashima ${ }^{2}$ and Fernando Mejia ${ }^{2}$
}

\begin{abstract}
Background: In clinical practice, identification of a case of severe asthma exacerbation prompts initiation of corticosteroids. However, not all that wheezes is asthma.

Case presentation: A 61-year-old man from the Peruvian Amazon presented with progressive dyspnea, abdominal pain, and cough for the past week. His medical history was remarkable for asthma since childhood; he was treated with beta-agonists, ipratropium, and orally administered corticosteroids. On evaluation, he was febrile and illappearing. His chest examination revealed diffuse wheezing and bilateral crackles. He was diagnosed as having community-acquired pneumonia and asthma exacerbation and was started on empiric antibiotics, nebulized beta-agonists, and orally administered corticosteroids. His clinical status continued deteriorating and he became critically ill despite broad-spectrum antibiotics and antifungals. Considering the epidemiological background of our patient, bronchoalveolar and fecal samples were obtained to investigate soil-transmitted helminths. Larvae of Strongyloides stercoralis were found in both specimens. Ivermectin was initiated and corticosteroids were discontinued. He experienced remarkable improvement of clinical condition over the next weeks. The literature on this topic was reviewed.
\end{abstract}

Conclusion: Cases of severe asthma exacerbation warrant careful evaluation before the initiation of corticosteroids, especially in patients at risk for parasitic infections. A high index of suspicion is critical. Alternative etiologies of respiratory decompensation should be considered in patients who fail to improve with broad-spectrum antibiotics and antifungals.

Keywords: Asthma, Corticosteroids, Strongyloidiasis, Strongyloides, Hyperinfection syndrome, Case report

\section{Background}

Strongyloides stercoralis is an intestinal nematode with a worldwide distribution [1]. Rural regions in tropical and subtropical countries are known to have a high prevalence of this organism $[1,2]$. Travelers, military personnel, and immigrants coming to developed countries can host this parasite for years without expressing any complaint [1-3]. Symptomatic strongyloidiasis may manifest with gastrointestinal (GI) complaints and asthma-like symptoms [4, 5]. However, patients undergoing immunosuppressive therapy or with severely debilitated immune status can develop an

\footnotetext{
* Correspondence: george.vasquez@upch.pe;

george.vasquezrios@health.slu.edu

'Department of Internal Medicine, Saint Louis University School of Medicine, Saint Louis, MO, USA

${ }^{2}$ Laboratory of Parasitology, Tropical Medicine Institute Alexander von

Humboldt, Universidad Peruana Cayetano Heredia, Lima, Peru

Full list of author information is available at the end of the article
}

unusual phenomenon known as hyperinfection syndrome (HS) $[6,7]$. HS is characterized by critical illness and multi-organ dysfunction due to massive dissemination of the parasite [6-8].

Discussions about the association between asthma and Strongyloides date back to the 1960s [9-11] and a few cases of patients with asthma suffering exacerbations attributed to $S$. stercoralis infection have been reported in the literature [12-34]. Although the underlying pathophysiology is still unclear, corticosteroid use during asthma exacerbations could trigger severe forms of disease, including Strongyloides HS [2-5]. Therefore, HS remains an obscure cause of respiratory distress among individuals with asthma with high mortality rates if the diagnosis is delayed [6-8].

This is a case report of a patient who survived an unusual presentation of hyperinfection by S. stercoralis, masquerading as an asthma exacerbation. There are 
limited data on patients who survived aggressive forms of Strongyloides HS especially after receiving high doses of corticosteroids [7]. Therefore, there is a need for further research to optimize current management recommendations. This study aims to provide critical care physicians and internists with clinical clues that may help them arrive at the diagnosis in a timely fashion as well as guide management.

\section{Review of the literature}

Two independent investigators (GVR and RPR) searched the literature to identify cases of Strongyloides HS in patients with asthma. Eligibility criteria were: (1) case reports including individuals with asthma exacerbation who tested positive for S. stercoralis by means of any fluid or solid specimen (stool, bronchial secretions); and (2) diagnosis of Strongyloides HS based on microscopic visualization of the larvae from bronchial secretions or through histopathology. Abstracts were reviewed in PubMed, EBSCO, LILACS, and SciELO. MeSH search terms included: "Strongyloides" AND "asthma"; "Strongyloides stercoralis" AND "asthma"; "Strongyloidiasis" AND "asthma". Also, we conducted a secondary search of the literature through Google/Google Scholar and reviewed previous references. Reports in English, French, or Spanish languages were included. Figure 1 presents the abstract screening process. Reports that met the eligibility criteria were analyzed in detail. The authors evaluated those articles and any discrepancy was solved by consensus. Data were collected in case forms and stored in a spreadsheet.

\section{Case presentation}

A 61-year-old man from the Peruvian Amazon presented to the Emergency Department with a 1-week history of progressive shortness of breath, fever, and cough. His medical background was significant for essential hypertension and asthma. His home medications included lisinopril, fluticasone/salmeterol, ipratropium, and low-dose prednisone. He worked as a farmer in the Peruvian rainforest and had no known environmental exposure to pollutants or toxins. He did not smoke tobacco but he was a former alcohol user who quit drinking alcohol 5 years before presentation. He had a family history of hypertension. On evaluation, he was ill-appearing and in respiratory distress. His vital signs were: temperature $(\mathrm{T})$ $38.2^{\circ} \mathrm{C}$, blood pressure $110 / 70 \mathrm{mmHg}$, heart rate 105 beats per minute (bpm), and respiratory rate 28 respirations $/ \mathrm{mi}^{-}$ nute with saturation of oxygen $\left(\mathrm{SO}_{2}\right) 87 \%$ on room air. Chest auscultation revealed diffuse wheezing and bilateral crackles. His cardiovascular examination showed tachycardia without gallops or murmurs. Furthermore, his neurological examination was negative for focal deficits or meningeal signs. The rest of the physical examination was unremarkable.

Initial laboratory results showed a white blood cell count of $34 \times 10^{9} / \mathrm{L}$ (bands $5 \%$, lymphocytes $1.7 \%$, eosinophils $0.3 \%$ ). Biochemical analysis revealed hyponatremia, mild elevation of hepatic enzymes, and severe hypoalbuminemia. His arterial blood gases revealed: $\mathrm{pH}$ 7.28, partial pressure of carbon dioxide $\left(\mathrm{pCO}_{2}\right) 55$ $\mathrm{mmHg}$, and partial pressure of oxygen $\left(\mathrm{pO}_{2}\right) 59 \mathrm{mmHg}$. A chest X-ray showed bilateral base-predominant interstitial infiltrates concerning for community-acquired pneumonia (Fig. 2). He was administered ceftriaxone and azithromycin, albuterol nebulization, and biphasic positive airway pressure support. In addition, a dose of prednisone $(1 \mathrm{mg} / \mathrm{kg})$ was administered orally for severe obstructive airway disease. He exhibited partial clinical improvement over the following 48 hours, but due to worsening oxygen requirements and persistent fever, his antibiotic therapy was switched to meropenem and vancomycin. Figure 3 shows a computed tomography (CT) scan with bilateral consolidations, predominantly on the lower lobe of his left lung.

On hospital day 5 , he presented hemodynamic instability and acute encephalopathy, which prompted intubation and vasopressor support. Arterial blood gases showed: $\mathrm{pH}$ 6.9, $\mathrm{pCO}_{2} 70.8 \mathrm{mmHg}$, and $\mathrm{pO}_{2} 51 \mathrm{mmHg}$. His lactic acid level was $10.7 \mathrm{mmol} / \mathrm{L}$. A repeat chest $\mathrm{CT}$ scan revealed extensive bilateral infiltrates and ground-glass opacities (Fig. 4). Empiric therapy with micafungin was initiated. Bronchoalveolar lavage (BAL) was negative for conventional bacteria, fungi, or acid-fast bacilli. An extensive work-up was unremarkable including investigations for HIV and Human T-cell lymphotropic virus (HTLV-1), which were non-reactive. Considering the patient epidemiological background and his rapid deterioration despite broad-spectrum antibiotics, a new BAL was conducted to test for soil-transmitted helminths (STH). Fecal samples were collected as well. Finally, larvae of $S$. stercoralis were found in both BAL (Fig. 5) and stool specimens (Fig. 6). Corticosteroid therapy was discontinued and anti-parasitic treatment was started with ivermectin $200 \mu \mathrm{g} / \mathrm{kg}$ per day orally for 2 days. Therapy was repeated 2 weeks later to ensure adequate parasite eradication. Stool and bronchial specimens were negative thereafter. The patient experienced progressive recovery over the next 4 weeks. Unfortunately, he was lost to follow-up afterward.

\section{Literature analysis}

Fourteen cases of asthma exacerbation associated with Strongyloides HS were identified (Table 1). The mean age was 58.6 years. The male-to-female ratio was 5:2. Of the individuals, $21 \%$ presented one or more comorbid conditions including ischemic heart disease, Cushing 


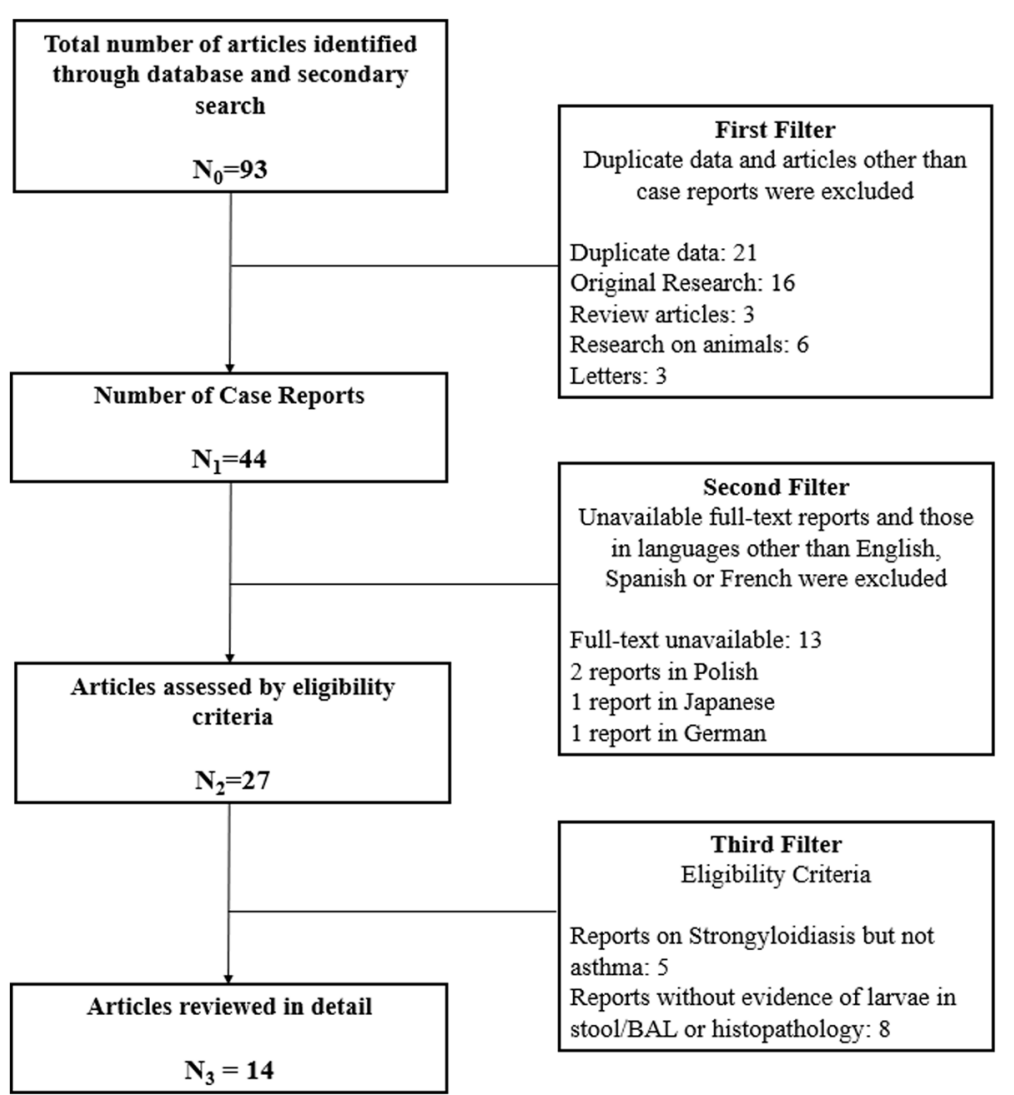

Fig. 1 Review of the literature. BAL bronchoalveolar lavage

syndrome, and rheumatoid arthritis. All except one were born in endemic areas for Strongyloides and one was born in a developed country but served as military personnel in a high-risk country for STH. More than half of the cases $(57 \%)$ were reports from health care centers in developed countries.

Among clinical manifestations, $64 \%$ of individuals presented with respiratory distress and $21 \%$ with GI symptoms. Fever was inconsistently reported. Two presented hemoptysis. Eosinophilia was reported in $20 \%$ of the cases that included this laboratory result (10 reports), while hypereosinophilia was seen in $30 \%$ of them. BAL and/or sputum were positive in $93 \%$ of cases, and the remaining individuals were diagnosed with Strongyloides HS by lung histopathology, which yielded numerous larvae during the autopsy. Stool examination was positive for larvae of Strongyloides in 67\% of those patients tested ( 8 out of 12). Anti-parasitic therapy was administered to $86 \%$ of individuals ( 12 out of $14)$; ivermectin was the drug of choice in $42 \%$ of the cases (5 out of 12). Two of those patients received ivermectin plus another anti-parasitic drug. Overall, the mortality rate was $46 \%$ (6 out of $13 ; 1$ outcome was unknown). Notably, individuals treated with ivermectin alone or in combination therapy had a survival rate of $100 \%$ (five out of five), while only $33 \%$ (two out of six) of those treated with a different anti-parasitic drug survived.

\section{Discussion}

This case report presents a patient with symptoms related to bronchial hyperresponsiveness, presumed to be an asthma exacerbation complicated by pneumonia and sepsis. Mild or absent eosinophilia with severe obstructive respiratory symptoms may lead clinical judgment toward common etiologies. However, a high degree of suspicion along with consideration of this patient's epidemiologic background were vital for appropriate investigation of the presence of $S$. stercoralis in BAL and stool samples. Compared to previous literature, this is an unusual case of a patient who survived septic shock, Strongyloides HS, and high-dose steroid therapy.

Strongyloidiasis has become an emergent disease in developed countries because of immigration. Ostera et al. detected a prevalence of $4.2 \%$ among Latin American immigrants in Washington DC, USA [34]. More than half of the cases included in the literature review (Table 1) were reported in developed countries including the USA, 


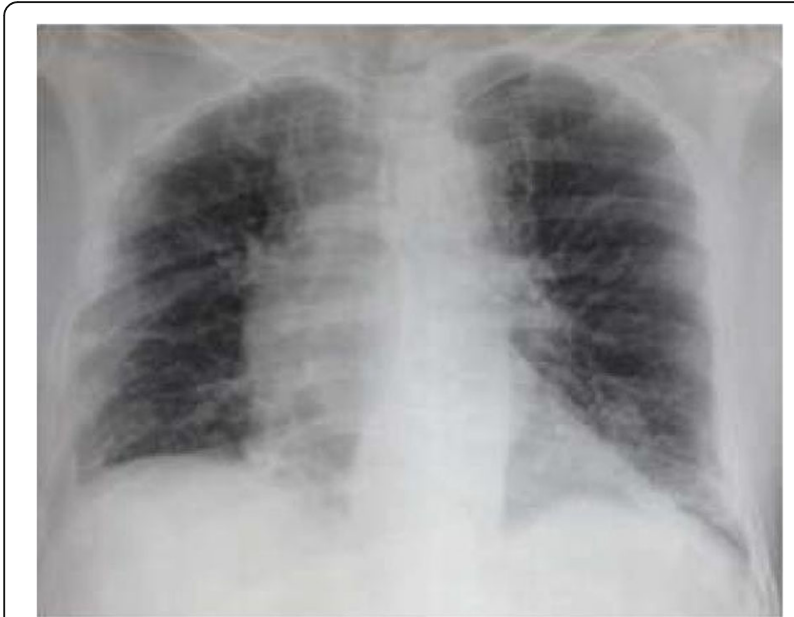

Fig. 2 Chest $X$-ray showing bilateral interstitial infiltrates, predominantly in the bases

England, France, and South Korea [13-18, 20, 24]. However, all the patients were exposed to endemic areas. This is an important finding, since the popularization of traveling and globalization could favor the presentation of Strongyloides in non-endemic areas, a trend noticed over the last 20 years $[2,5]$.

Clinical manifestations of $S$. stercoralis infection may range from asymptomatic to chronic symptoms, and Strongyloides HS with multiple systems involved [2, 4]. Strongyloides HS is the result of the high replication and migration of the larvae, typically seen in patients with impaired cell-mediated immunity as in those with HTLV-1 infection, transplant recipients, or individuals on chronic or high-dose corticosteroids $[2,4,7,8]$. On the other hand, HIV has not been frequently associated with Strongyloides HS [2, 3]. It usually presents with fever and GI complaints (for example, nausea, vomiting,

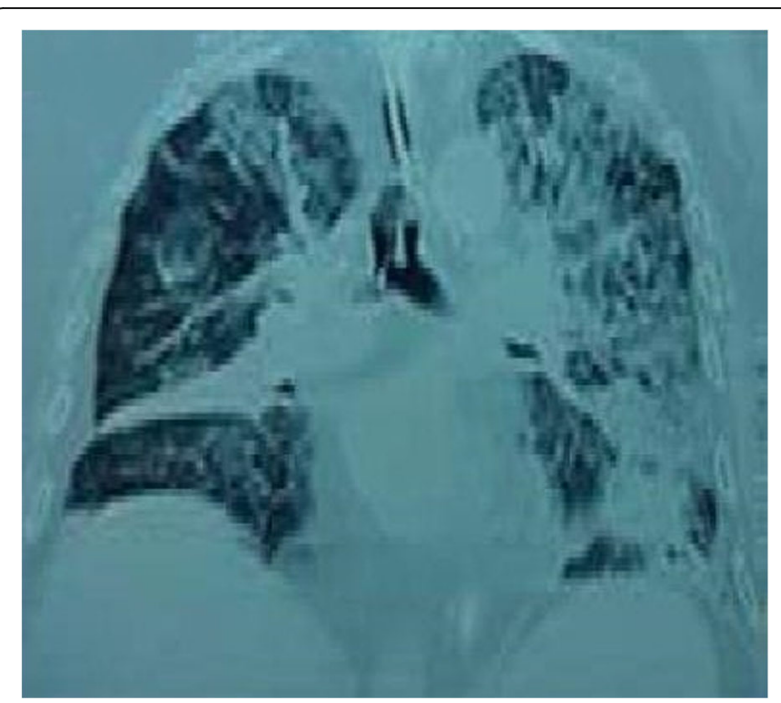

Fig. 4 Repeat chest computed tomography scan showing diffuse interstitial infiltrates and consolidations

abdominal pain, diarrhea, bleeding); however, extra-intestinal manifestations are also common, including dyspnea, wheezing, pulmonary infiltrates, or alveolar hemorrhage [2-4]. Strongyloides HS may be complicated with shock, disseminated intravascular coagulation, and respiratory failure $[2,4,7,8]$. Interestingly, the main presentation of Strongyloides HS noticed in the literature review, as well as in this case, was pulmonary involvement (64\%) as opposed to the expected GI manifestation caused by helminths.

Strongyloides infection in healthy individuals characteristically produces marked eosinophilia [2-5]. In contrast, patients with Strongyloides HS may present with a higher number of larvae but few eosinophils $[2,5,8]$. Increased eosinophil count was observed in half of cases with available data (five out of ten patients); and it was

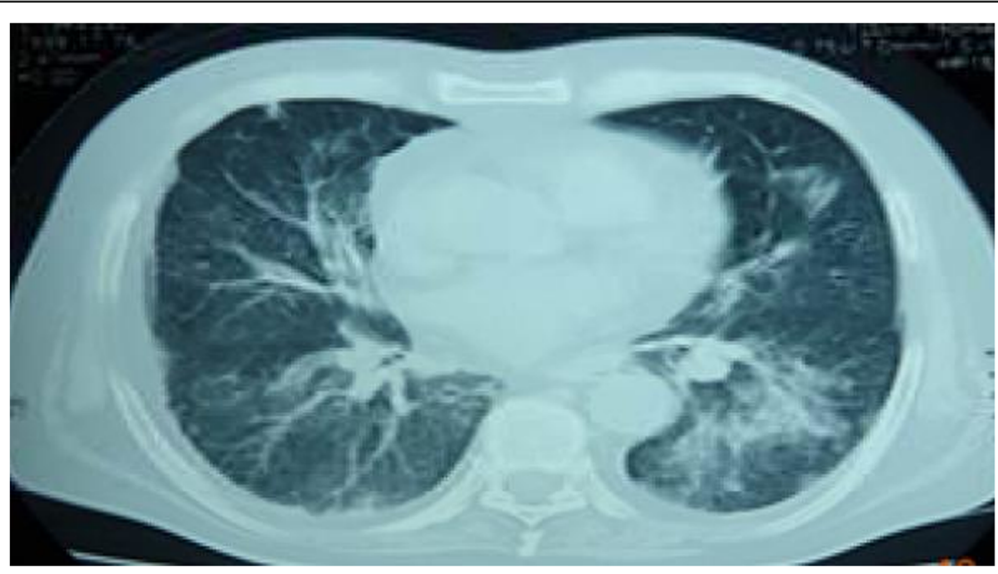

Fig. 3 Chest computed tomography scan revealing ground-glass opacities and interstitial infiltrates bilaterally, predominantly in the left side 


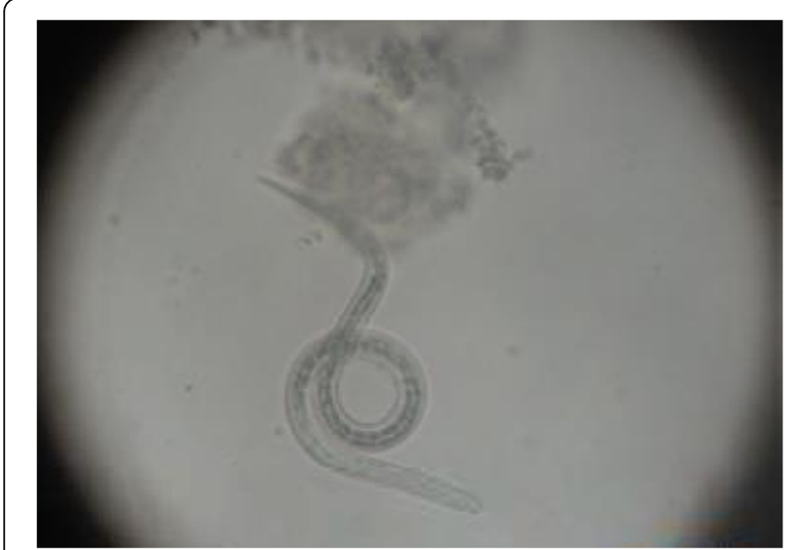

Fig. 5 Strongyloides stercoralis larvae found in bronchoalveolar lavage

present only in one third of patients who died. Our patient did not have eosinophilia. As stated before, corticosteroid therapy is one of the most frequent risk factors for Strongyloides HS in developed countries and may contribute to an adverse outcome [5, 7]. Corticosteroids affect T-helper type-2 (Th2) response and eosinophil migration to the site of infection. Also, there is evidence suggesting that corticosteroids can play a role as molting signals for eggs, which enhances parasite production and promotes dissemination [2-5].

Although malnutrition and HTLV-1 infection are strong risk factors for strongyloidiasis in developing countries [2], this information was unavailable from the literature review. The patient had low albumin levels, probably reflecting his defective nutrition. He also tested negative for HIV and HTLV-1. The latter is especially important in Strongyloides HS, as it may induce a predominant Th1 cell response with high levels of interferon- $\gamma$ (IFN- $\gamma$ ) and tumor necrosis factor- $\alpha$ (TNF- $\alpha$ ). Furthermore, there is a

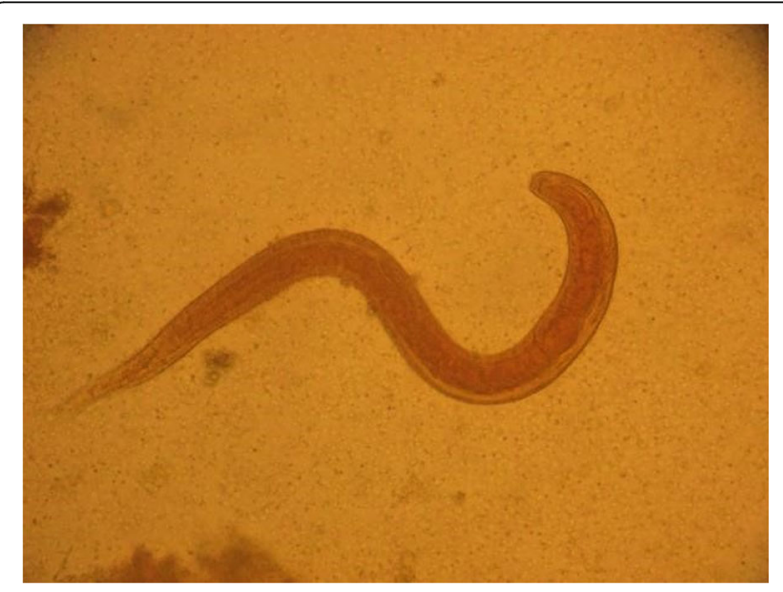

Fig. 6 Strongyloides stercoralis larvae found in stool examination decreased Th2 response that impairs the secretion of interleukin (IL)-4, IL-13, IL-5, and Ig E, which further reduces eosinophil recruitment and blunts the normal inflammatory response against the parasite $[3,5]$. Thus, investigation of HTLV-1 status is mandatory in patients with strongyloidiasis.

Examinations revealing larvae in bronchial fluids are an important criterion for confirming Strongyloides HS and dissemination [5]. Traditional stool-based techniques have low sensitivity $(<50 \%)$ for Strongyloides detection [35] and require multiple repeated examinations or concentration methods (such as Baermann) to increase its sensitivity [2, 3, 7]. However, it is hypothesized that in cases of Strongyloides HS, the larvae output is higher and the sensitivity of stool-based methods may increase $[2,3]$. In this review, one third of the cases had negative stool samples (4 out of 12), which could be explained by deficient sample collection in critically ill patients, insufficient number of stool samples provided for analysis, or lack of laboratory expertise. Molecular-based studies including enzyme-linked immunosorbent assay (ELISA) tests have the highest sensitivity (near 100\%) [36]; however, their availability, cost, and time-to-result may limit their role in an intensive care unit.

Suspicion of Strongyloides HS warrants immediate anti-parasitic treatment since mortality rates may be as high as $87 \%$ [6]. A recommended regimen is ivermectin $200 \mu \mathrm{g} / \mathrm{kg}$ per day for 2 days, repeated during the second and fourth week [3]. A single dose of ivermectin $200 \mu \mathrm{g} /$ $\mathrm{kg}$ has been demonstrated to be superior to a 7-day course of albendazole $800 \mathrm{mg}$ (93\% versus $63 \%$ success rate) [37]. In this review, three patients who received albendazole but not ivermectin ultimately expired. Two patients who did not receive any anti-parasitic drug also died. However, $100 \%$ of the individuals who received ivermectin alone or in combination with another anti-parasitic drug survived. Overall mortality rate was $46 \%$ in our patient cohort, which is concordant with the previously reported literature (15-87\%) [5]. There is limited evidence for the use of parenteral ivermectin and its use is restricted in clinical practice.

\section{Conclusion}

Strongyloides HS should be suspected in critically ill patients with asthma with a pertinent epidemiological background, and for whom conventional breathing therapy and broad-spectrum antibiotics failed. Once the diagnosis of Strongyloides infection is established, corticosteroids should be discontinued and therapy with ivermectin should be initiated promptly. A high index of suspicion and epidemiological risk assessment are the cornerstone for the diagnosis of this condition in both developed and developing countries. 


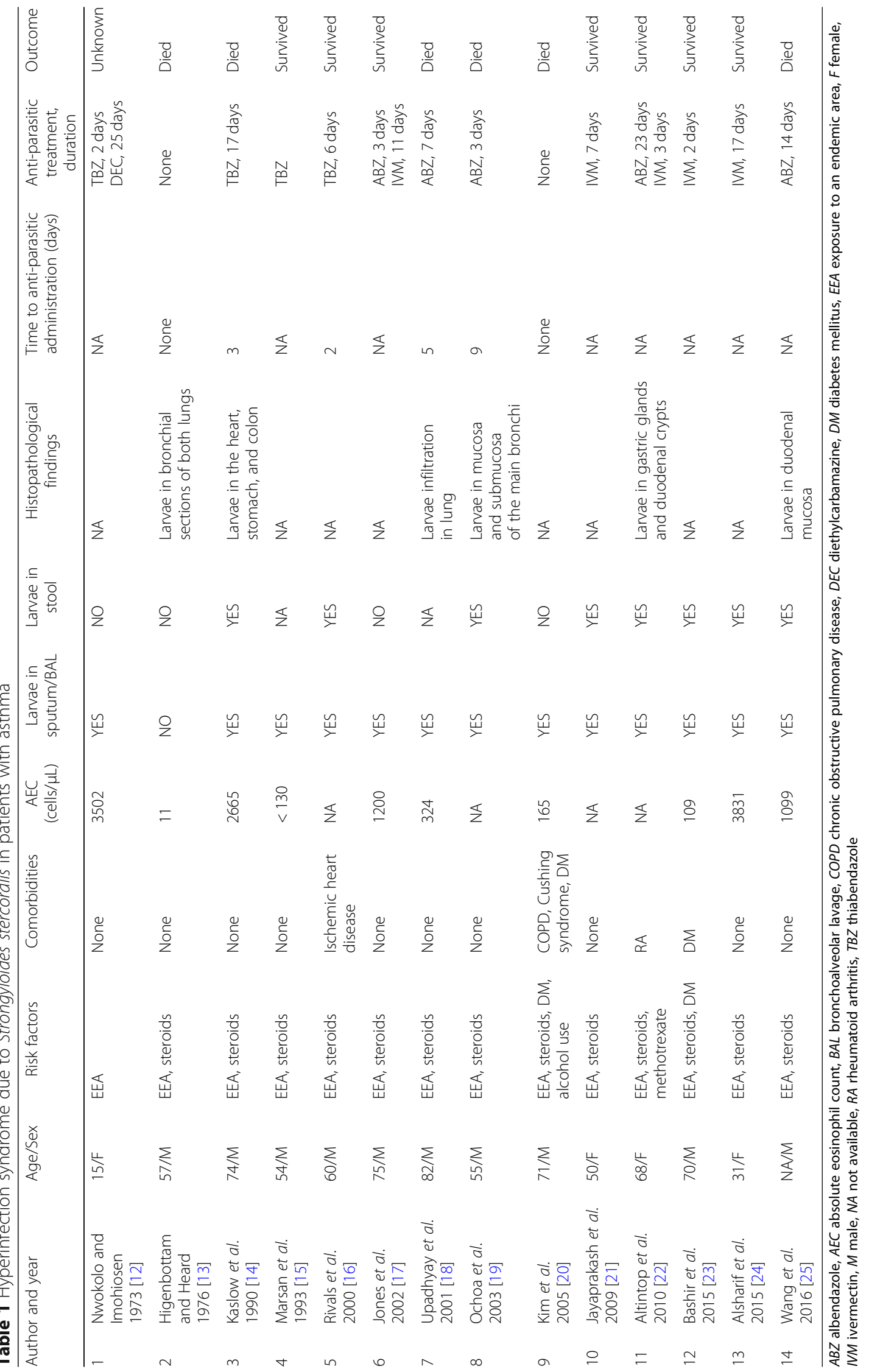




\section{Abbreviations}

BAL: Bronchoalveolar lavage; bpm: Beats per minute; CT: Computed tomography; ELISA: Enzyme-linked immunosorbent assay; GI: Gastrointestinal; HIV: Human immunodeficiency virus; HS: Hyperinfection syndrome; HTLV1: Human T-cell lymphotropic virus; IFN- $\gamma$ : interferon- $\gamma$; IL: Interleukin; $\mathrm{pCO}_{2}$ : Partial pressure of carbon dioxide; $\mathrm{pO}_{2}$ : Partial pressure of oxygen; $\mathrm{SO}_{2}$ : Saturation of oxygen; STH: Soil-transmitted helminths; T: Temperature; Th2: T-helper type-2; TNF-a: Tumor necrosis factor-a

\section{Acknowledgements}

The authors would like to express their gratitude to the personnel of the Laboratory of Parasitology at the Tropical Medicine Institute "Alexander von Humboldt."

\section{Funding}

No specific funding was obtained.

\section{Availability of data and materials}

All data, images, and results are available from the corresponding author on reasonable request.

\section{Authors' contributions}

GV-R and RP-R drafted the manuscript. GV-R and RP-R conducted the literature review. GV-R, RP-R, EFR, and FM were part of the medical team responsible for the patient. AT and FM provided expert consultation during the management of the patient and in the elaboration of this manuscript. GV-R, RP-R, EFR, AT, and FM provided significant intellectual contributions and technical support to this manuscript. All the authors critically evaluated the manuscript and accepted the final edition of it. All authors read and approved the final manuscript.

\section{Ethics approval and consent to participate}

The CARE guidelines were thoroughly followed to present the case report.

\section{Consent for publication}

Written informed consent was obtained from the patient for publication of this case report and any accompanying images. A copy of the written consent is available for review by the Editor-in-Chief of this journal.

\section{Competing interests}

The authors declare that they have no competing interests.

\section{Publisher's Note}

Springer Nature remains neutral with regard to jurisdictional claims in published maps and institutional affiliations.

\section{Author details}

'Department of Internal Medicine, Saint Louis University School of Medicine, Saint Louis, MO, USA. ${ }^{2}$ Laboratory of Parasitology, Tropical Medicine Institute Alexander von Humboldt, Universidad Peruana Cayetano Heredia, Lima, Peru. ${ }^{3}$ CONEVID, Unidad de Conocimiento y Evidencia, Universidad Peruana Cayetano Heredia, Lima, Peru.

Received: 4 December 2018 Accepted: 18 February 2019

Published online: 29 April 2019

\section{References}

1. Schär F, Trostdorf U, Giardina F, Khieu V, Muth S, Marti H, et al. Strongyloides stercoralis: Global Distribution and Risk Factors. PLoS Negl Trop Dis. 2013; 7(7):e2288.

2. Barros N, Montes M. Infection and Hyperinfection with Strongyloides stercoralis: Clinical Presentation, Etiology of Disease, and Treatment Options. Curr Trop Med Rep. 2014;1:223-8.

3. Marcos L, Terashima A, Canales M, Gotuzzo E. Update on Strongyloidiasis in the Immunocompromised Host. Curr Infect Dis Rep. 2011:13(1):35-46.

4. Vadlamudi R, Chi DS, Krishnaswamy G. Intestinal strongyloidiasis and hyperinfection syndrome. Clin Mol Allergy. 2006:4:8.

5. Marcos LA, Terashima A, Dupont HL, Gotuzzo E. Strongyloides hyperinfection syndrome: an emerging global infectious disease. Trans R Soc Trop Med Hyg. 2008;102(4):314-8
6. Buonfrate D, Requena-Mendez A, Angheben A, Muñoz J, Gobbi F, Van Den Ende J, et al. Severe strongyloidiasis: a systematic review of case reports. BMC Infect Dis. 2013;13:78.

7. Vasquez-Rios G, Pineda-Reyes R, Pineda-Reyes J, Marin R, Ruiz EF, Terashima A. Strongyloides stercoralis hyperinfection syndrome: a deeper understanding of a neglected disease. J Parasit Dis. 2019; https://doi.org/10.1007/s12639019-01090-x

8. Geri G, Rabbat A, Mayaux J, Zafrani L, Chalumeau-Lemoine L, Guidet B, et al. Strongyloides stercoralis hyperinfection syndrome: a case series and a review of the literature. Infection. 2015;43(6):691-8.

9. Tullis DC. Bronchial asthma associated with intestinal parasites. N Engl J Med. 1970;282(7):370-2.

10. Salako LA, Sofowora EO. Bronchial asthma associated with intestinal parasites. N Engl J Med. 1970;283(5):264-5.

11. Van Dellen RG, Thompson JH Jr. Absence of intestinal parasites in asthma N Engl J Med. 1971;285(3):146-8.

12. Nwokolo C, Imohiosen EA. Strongyloidiasis of respiratory tract presenting as "asthma". Br Med J. 1973;2(5859):153-4.

13. Higenbottam TW, Heard BE. Opportunistic pulmonary strongyloidiasis complicating asthma treated with steroids. Thorax. 1976;31(2):226-33.

14. Kaslow JE, Novey HS, Zuch RH, Spear GS. Disseminated strongyloidiasis: an unheralded risk of corticosteroid therapy. J Allergy Clin Immunol. 1990; 86(1):138

15. Marsan C, Marais MH, Sollet JP, Le Turdu F, Guerin PH, Garcia R, et al. Disseminated strongyloidiasis: a case report. Cytopathology. 1993:4(2):123-6.

16. Rivals A, Rouquet RM, Recco P, Linas MD, Leophonte P, Didier A. A rare cause of asthma exacerbation: systemic anguilluliasis. Rev Mal Respir. 2000; 17(1):99-102.

17. Jones N, Tran J, Naito S, Taylor P, Tran B. Strongyloides-induced Respiratory Failure. Int J Trop Med. 2002;1(1):1-7.

18. Upadhyay D, Corbridge T, Jain M, Shah R. Pulmonary hyperinfection syndrome with Strongyloides stercoralis. Am J Med. 2001:111(2):167-9.

19. Ochoa MD, Ramírez-Mendoza P, Ochoa G, Vargas MH, Alba-Cruz R, Rico-Méndez FG. Bronchial nodules produced by Strongyloides stercoralis as the cause of bronchial obstruction. Arch Bronconeumol. 2003;39(11): 524-6.

20. Kim J, Joo HS, Ko HM, Na MS, Hwang SH, Im JC. A case of fatal hyperinfective strongyloidiasis with discovery of autoinfective filariform larvae in sputum. Korean J Parasitol. 2005;43(2):51-5.

21. Jayaprakash B, Sandhya S, Anithakumari K. Pulmonary strongyloidiasis. J Assoc Physicians India. 2009;57:535-6.

22. Altintop L, Cakar B, Hokelek M, Bektas A, Yildiz L, Karaoglanoglu M. Strongyloides stercoralis hyperinfection in a patient with rheumatoid arthritis and bronchial asthma: a case report. Ann Clin Microbiol Antimicrob. 2010;9:27.

23. Bashir G, Khan MA, Wani FA, Sofi BA. Hyperinfection with Strongyloides stercoralis in an asthmatic patient on corticosteroids. Int J Adv Res. 2015;3(1): 227-30

24. Alsharif A, Sodhi A, Murillo LC, Headley AS, Kadaria D. Wait!!! No Steroids for this Asthma.... Am J Case Rep. 2015:16:398-400.

25. Wang Y, Ma Y, Xu Y, Zhu B, Guo H. Strongyloides stercoralis disseminated infection in a patient misdiagnosed with chronic asthmatic bronchitis. J Microbiol Immunol Infect. 2016;49(1):154-6.

26. Dokmeci O, Forshay B, Scholand SJ. Worms on the brain: fatal meningoencephalitis from disseminated Strongyloides infection. Conn Med. 2013;77(1):31-3.

27. Kabirdas D, Afonso B, Avella H, Kanwar A, Berho M, Oliveira E. An elderly woman with asthma, eosinophilia, and septic shock. Cleve Clin J Med. 2007; 74(12):877-81. 885-6

28. Lozano Polo JL, Velasco Rubio A, Salas Venero C, García Ogando V. Strongyloides stercolaris and bronchial asthma. Rev Clin Esp. 2005;205(10): 519-20.

29. [No authors listed]. Case records of the Massachusetts General Hospital. Weekly clinicopathological exercises. Case 47-1987. A 79-year-old Cuban native with asthma, weight loss, vomiting, eosinophilia, and past meningitis. N Engl J Med. 1987;317(21):1332-42.

30. Mokhlesi B, Shulzhenko O, Garimella PS, Kuma L, Monti C. Pulmonary Strongyloidiasis: The Varied Clinical Presentations. Clin Pulm Med. 2004;11(1) $6-13$

31. Robinson J, Ahmed Z, Siddiqui A, Roy T, Berk S, Smith JK, et al. A patient with persistent wheezing, sinusitis, elevated lgE, and eosinophilia. Ann Allergy Asthma Immunol. 1999;82(2):144-9. 
32. Sen P, Gil C, Estrellas B, Middleton JR. Corticosteroid-induced asthma: a manifestation of limited hyperinfection syndrome due to Strongyloides stercoralis. South Med J. 1995;88(9):923-7.

33. Shea YF, Mok WW, Chan JF, Kwan JS. A hidden cause of recurrent asthmatic attacks. J Am Geriatr Soc. 2014;62(7):1408-9.

34. Ostera G, Blum J, Cornejo C, Burgula S, Jeun R, Bryan PE, et al. Strongyloidiasis in Latin American immigrants: a pilot study. J Helminthol. 2017:91(2):262-6.

35. Boulware DR, Stauffer WM 3rd, Walker PF. Hypereosinophilic syndrome and mepolizumab. N Engl J Med. 2008;358(26):2839. author reply 2839-40

36. Bisoffi Z, Buonfrate D, Sequi M, Mejia R, Cimino RO, Krolewiecki AJ, et al. Diagnostic accuracy of five serologic tests for Strongyloides stercoralis infection. PLoS Negl Trop Dis. 2014:8(1):e2640.

37. Suputtamongkol Y, Premasathian N, Bhumimuang K, Waywa D, Nilganuwong S, Karuphong E, et al. Efficacy and safety of single and double doses of ivermectin versus 7-day high dose albendazole for chronic strongyloidiasis. PLoS Negl Trop Dis. 2011;5(5):e1044.

Ready to submit your research? Choose BMC and benefit from:

- fast, convenient online submission

- thorough peer review by experienced researchers in your field

- rapid publication on acceptance

- support for research data, including large and complex data types

- gold Open Access which fosters wider collaboration and increased citations

- maximum visibility for your research: over $100 \mathrm{M}$ website views per year

At BMC, research is always in progress.

Learn more biomedcentral.com/submissions 